\title{
ANALISA ALGORITMA RELIEFF UNTUK MODEL ASOSIASI PERUBAHAN WARNA PADA INDIKATOR KEMASAN CERDAS DAN PERUBAHAN MUTU PRODUK
}

\author{
Elfa Susanti Thamrin ${ }^{1}$, Endang Warsiki ${ }^{2}$, Taufik Djatna ${ }^{2}$ \\ ${ }^{1}$ Institut Teknologi Sumatera, Lampung, Indonesia \\ ${ }^{2}$ Departemen Teknologi Industri Pertanian, Fakultas Teknologi Pertanian, Institut Pertanian Bogor, \\ Bogor, Indonesia
}

\begin{abstract}
Smart packaging is one of innovations in the field of packaging that can monitor and provide information to producers and consumers about the quality of the packaged product. Nowadays, there is no exact model to relate both of the changing between the label and the product quality. Thus, it is required an association between discoloration smart packaging indicator with the packaged product quality change. Parameter identification process can generate a lot of parameters, we need a method to select the important parameter attributes therefore it used a ReliefF (Reliable Eliminated of Feature) method. The objectives of this research were to identify the association parameters and to select the important attribute and sufficiently describing the relationship and furthermore this research was to develop an association model of discoloration of smart packaging indicator with natural dyes and the quality changes. The data were obtained from a previous research and discretization to classify the data ${ }^{\circ} \mathrm{Hue}, \Delta E$, consumer preferences and the total colony to nominal value. Selection of attributes by using the ReliefF method showed that there were three attributes with the highest weight value $\left(W_{i}\right)$. Furthermore, this research generated important parameters and sufficiently describing the relationship of discoloration and product quality changes.
\end{abstract}

Keyword: Smart packaging, association, ReliefF, discoloration, product quality changes

\section{Pendahuluan}

Pengemasan cerdas / kemasan cerdas melakukan pengawasan kondisi makanan dengan menggunakan indikator yang dibedakan atas indikator luar dan indikator dalam. Kemasan cerdas dengan indikator warna telah banyak diaplikasikan pada berbagai jenis produk yang rentan terhadap suhu panas dan produk yang harus disimpan dalam kondisi dingin, antara lain produk seafood [1; 2; 3], produk olahan susu [4], produk buah dan sayur [5;6], produk daging [7 ; 8]. Perubahan warna juga menginformasikan bahwa produk terkena paparan dari suhu yang tidak seharusnya atau penanganan penyimpanan yang tidak sesuai [9].

Kemasan cerdas merupakan indikator yang sangat penting bagi konsumen mendapatkan informasi untuk meminimalkan yang berhubungan dengan resiko kadaluarsa penyimpanan yang berdampak pada kualitas produk. Perubahan warna sejalan dengan terjadinya perubahan mutu produk selama masa penyimpanan dan saat ini belum ada perhitungan kuantifikasi yang menghubungkan keduanya. Sehingga, dibutuhkan sebuah model asosiasi antara perubahan warna indikator kemasan cerdas dengan terjadinya perubahan kualitas produk yang dikemas.

Salah satu teknik yang dapat digunakan untuk menghubungkan suatu kombinasi adalah dengan menerapkan algoritma apriori. Algoritma apriori merupakan salah satu teknik dalam data mining untuk pengambilan data dengan menggunakan aturan hubungan asosiatif (Association rules) dari suatu kombinasi item.

Sebelum dilakukan pemodelan asosiasi, dibutuhkan suatu identifikasi parameter-parameter yang akan digunakan dalam pemodelan. Identifikasi parameter dapat dilakukan dengan studi literatur dan pengumpulan data primer atau sekunder. Proses identifikasi parameter dapat menghasilkan banyak parameter sehingga dibutuhkan suatu metode untuk memilih atribut parameter yang penting dan cukup untuk menggambarkan hubungan antara perubahan warna indikator dan perubahan mutu produk, oleh karena itu peneliti melakukan proses reduksi data. Feature selection merupakan cara yang efektif untuk melakukan reduksi data dan menjadi langkah penting agar aplikasi data mining 
berjalan dengan baik [10]. Salah satu teknik feature selection yang berkembang saat ini yaitu metode ReliefF (Reliable Eliminated of Feature). ReliefF merupakan algoritma pemilihan atribut pada binary classification [11].

Metode ReliefF memberikan estimasi atribut yang efisien dengan menghitung nilai perbedaan jarak antar instan. Perbedaan jarak tersebut akan digunakan untuk menghitung nilai bobot. Pengukuran jarak pada metode ReliefF ada 2 macam, yaitu nearhit dan nearmiss. Nearhit merupakan jarak antar instan dalam satu kelas, sedangkan nearmiss adalah jarak antar instan yang berbeda kelas [12].

Penelitian terkait asosiasi antara perubahan warna terhadap perubahan mutu produk yang diaplikasikan kemasan cerdas masih terbatas. Tujuan dari penelitian ini yaitu mengidentifikasi parameter asosiasi, memilih atribut yang penting dan cukup untuk menggambarkan hubungan dan mengembangkan model asosiasi perubahan warna indikator kemasan cerdas dengan pewarna alami dan perubahan mutu produk.

\section{Metode}

\subsection{Alat Penelitian}

Penelitian ini menggunakan perangkat lunak spreadsheet pada PC Notebook berprocessor core-i5 4 GByte RAM.

\subsection{Kerangka Pemikiran}

Alur kegiatan penelitian dapat dilihat pada Gambar 1. Tahapan penelitian diawali dengan mengidentifikasi parameter yang digunakan dalam analisa asosiasi dengan mengumpulkan data sekunder dari penelitian sebelumnya, kemudian memilih atribut parameter yang penting.

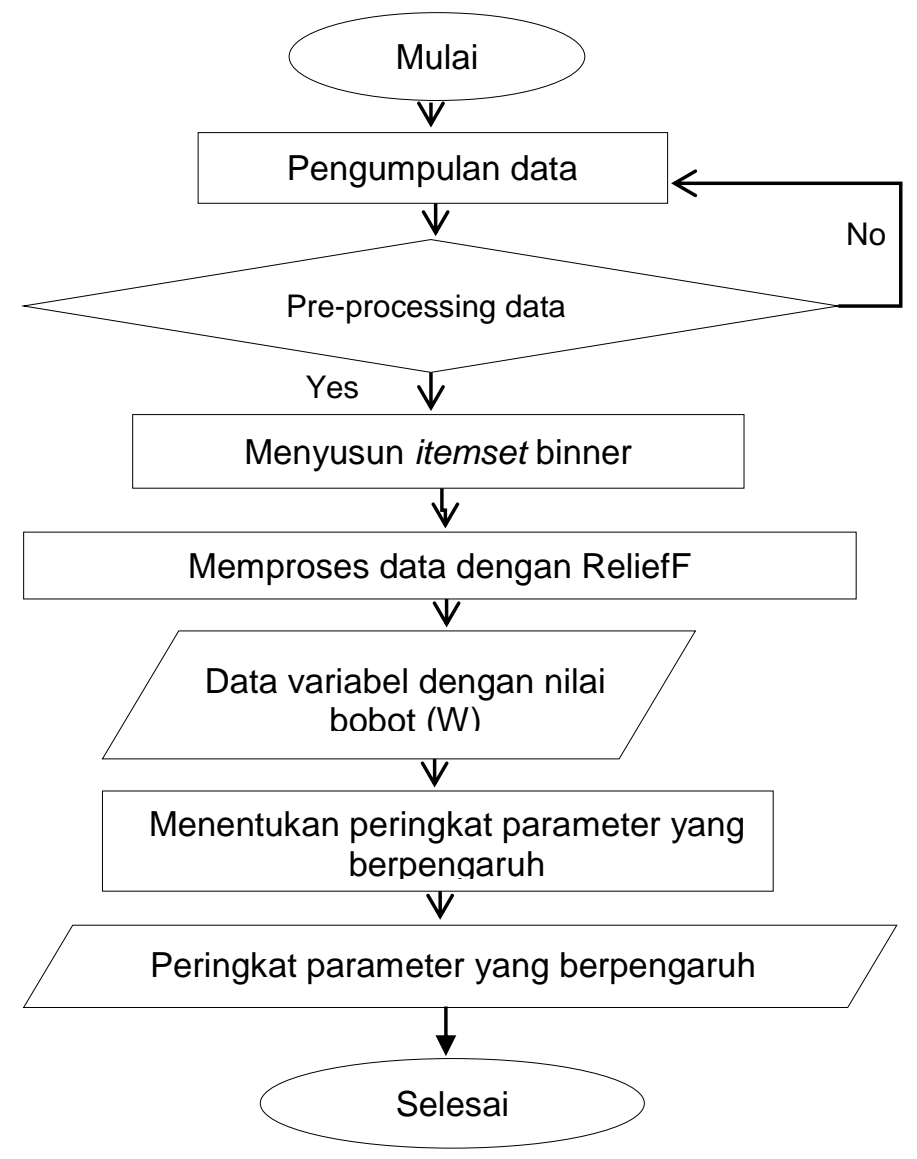

Gambar 1. Kerangka Pemikiran Penelitian 


\subsection{Prosedur Penelitian}

\subsubsection{Identifikasi Parameter Asosiasi}

Parameter asosiasi yang digunakan pada penelitian ini diidentifikasi dari studi literatur dan data sekunder dari hasil penelitian [4] meliputi parameter perubahan warna, parameter perubahan mutu produk, perubahan warna dari label indikator kemasan cerdas, waktu dan suhu penyimpanan produk. Parameter yang digunakan dalam penelitian ini disesuaikan dengan kebutuhan analisa asosiasi.

Selanjutnya dilakukan pre-processing jika terdapat masalah pada data yang didapat, seperti jumlah populasi data terlalu besar, banyak data yang menyimpang, dan dimensi terlalu tinggi. Salah satu metode dalam pre-processing dengan melakukan diskretisasi. Setelah itu, menyusun data yang telah didiskretisasi ke dalam tabel tabular dalam bentuk biner.

\subsubsection{Analisa Pemilihan Atribut}

Data biner yang telah diinput ke dalam tabel tabular diolah menggunakan metode ReliefF [11] untuk memilih atribut parameter yang penting dan cukup untuk menggambarkan hubungan dari perubahan warna dan perubahan mutu produk. Tahapan metode ini dengan menghitung bobot masing-masing variabel kemudian menentukan parameter yang berpengaruh terhadap perubahan warna label indikator. Perhitungan nilai bobot dengan menggunakan software WEKA versi 3.6.

\section{Hasil dan Pembahasan}

\subsection{Identifikasi Parameter}

Data diperoleh dari penelitian sebelumnya yang dilakukan oleh [4], berupa data nilai ${ }^{\circ}$ Hue, nilai $L^{*}$, nilai $a^{*}$, nilai $b^{*}$, nilai uji organoleptik (kesukaan konsumen) dan total koloni produk pada penyimpanan produk susu dengan label indikator kemasan cerdas dari daun erpa pada suhu $3 \pm 2^{\circ} \mathrm{C}$ yang disimpan dalam refrigerator selama 12 hari. Hal ini dikarenakan penyimpanan pada suhu tersebut merupakan perlakuan terbaik dari 4 jenis perlakuan (penyimpanan suhu freezer, suhu refrigerator, suhu ruang, dan suhu luar dengan paparan cahaya). Peneliti melakukan pengamatan nilai ${ }^{\circ} \mathrm{Hue}$, nilai $\mathrm{L}^{*}$, nilai $\mathrm{a}^{*}$, nilai $b^{*}$, kesukaan panelis terhadap produk dan total koloni produk sejak hari ke-0 penyimpanan. Nilai $L^{*}$, nilai $a^{*}$, nilai $b^{*}$ kemudian dihitung dengan persamaan (1) untuk mendapat nilai $\Delta E$. Data-data ini yang kemudian dijadikan data sekunder pada penelitian ini.

$$
\Delta E=\sqrt{\left[(\Delta \mathrm{L} *)^{2}+(\Delta \mathrm{a} *)^{2}+(\Delta \mathrm{b} *)^{2}\right]}
$$

Pada Tabel 1, data didiskretisasi untuk mengklasifikasikan data ${ }^{\circ} \mathrm{Hue}$, nilai $\Delta \mathrm{E}$, nilai kesukaan konsumen dan total koloni menjadi nilai nominal. Hal ini untuk memudahkan peneliti mengasosiasikan masing-masing itemsets. Kemudian, data yang sudah didiskretisasi dimasukkan ke dalam tabel tabular dan menggunakan bilangan biner "1" jika ada data pada item sets dan "0" jika tidak ada data dan dihitung nilai support dari masing-masing itemset.

\begin{tabular}{|l|l|l|l|}
\hline \multicolumn{1}{|c|}{ Nilai ${ }^{\circ H u e}$} & \multicolumn{1}{|c|}{ Nilai $\Delta \mathrm{E}$} & \multicolumn{1}{c|}{ Nilai kesukaan } & \multicolumn{1}{c|}{ Total Koloni } \\
\hline Merah $=18-54$ & Rendah $=0-13,67$ & Suka $=100-83,34$ & Aman $=<5 \times 10^{4}$ \\
\hline $\begin{array}{l}\text { Merah Kekuningan } \\
=54-90\end{array}$ & $\begin{array}{l}\text { Medium }=13,68- \\
27,34\end{array}$ & Tidak suka $=83,23-26,67$ & $\begin{array}{l}\text { Terkontaminasi }=>5 \times \\
10^{4}\end{array}$ \\
\hline Kuning $=90-126$ & Tinggi $=27,34-40$ & & \\
\hline
\end{tabular}

Tabel 1. Data Diskretisasi 
Setelah itu, data dalam tabel tabular dipilih atribut parameter yang penting dengan metode ReliefF dan kemudian dikembangkan model hubungan antara perubahan warna indikator kemasan cerdas dengan perubahan kualitas mutu produk susu dengan menggunakan metode ARM (Association Rules Mlning).

\subsection{Pemilihan Atribut}

Hasil analisa dengan menggunakan metode ReliefF menunjukkan bahwa terdapat empat kombinasi variabel dengan nilai bobot $\left(\mathrm{W}_{\mathrm{i}}\right)$ tertinggi. Perhitungan nilai $\mathrm{W}$ (weight) dengan menggunakan metode ReliefF pada software WEKA 3.6.

Variabel-x (parameter mutu) terdiri dari nilai ${ }^{\circ} \mathrm{Hue}(\mathrm{x} 1)$, nilai $\Delta \mathrm{E}(\mathrm{x} 2)$, nilai hedonik (x3), dan total koloni (x4). Sedangkan variabel-y merupakan perubahan warna indikator kemasan cerdas yang terdiri dari warna merah (y1), merah kekuningan (y2) dan kuning (y3).

\begin{tabular}{|c|c|c|c|c|c|c|c|c|c|c|c|}
\hline \multirow{2}{*}{$\begin{array}{c}\text { Variabel } \\
\text { warna }\end{array}$} & \multicolumn{3}{|c|}{$\mathrm{x} 1$} & \multicolumn{3}{c|}{$\mathrm{x} 2$} & \multicolumn{2}{|c|}{$\mathrm{x} 3$} & \multicolumn{2}{|c|}{$\mathrm{x} 4$} & $\mathrm{~W}$ \\
\cline { 2 - 12 } & $\mathrm{x} 1_{\mathrm{a}}$ & $\mathrm{x} 1_{\mathrm{b}}$ & $\mathrm{x} 1_{\mathrm{c}}$ & $\mathrm{x} 2_{\mathrm{d}}$ & $\mathrm{x} 2_{\mathrm{e}}$ & $\mathrm{x} 2_{\mathrm{f}}$ & $\mathrm{x} 3_{\mathrm{g}}$ & $\mathrm{x} 3_{\mathrm{h}}$ & $\mathrm{x} 4_{\mathrm{i}}$ & $\mathrm{x} 4_{\mathrm{j}}$ & $\mathrm{maks}$ \\
\hline $\mathrm{y}$ & $-0,354$ & 0,19 & 0,121 & 0,262 & 0,171 & 0,121 & 0,148 & 0,148 & 0,121 & 0,121 & 0,262 \\
\hline $\mathrm{y} 2$ & $-0,010$ & $-0,446$ & $-0,013$ & $-0,066$ & $-0,039$ & $-0,013$ & $-0,059$ & $-0,059$ & $-0,013$ & $-0,013$ & $-0,010$ \\
\hline $\mathrm{y3}$ & 0,264 & 0,321 & $-0,262$ & 0,295 & 0,295 & $-0,262$ & 0,423 & 0,423 & $-0,262$ & $-0,262$ & 0,423 \\
\hline
\end{tabular}

Tabel 2. Penentuan bobot maksimum variable-x terhadap variabel-y

Pada Tabel 2 nilai bobot tertinggi yang mempengaruhi $y 1$ adalah $x 2 d$ sebesar 0.262 . Setelah itu variabel-y diurutkan berdasarkan bobot maksimum yang tertinggi untuk menentukan faktor yang mempengaruhi perubahan warna indikator kemasan cerdas dan menjadi faktor penentu . Hal ini dapat dilihat pada Tabel 3.

\begin{tabular}{|c|c|c|c|}
\hline Parameter Mutu & Warna Indikator & Visualisasi & Nilai Bobot \\
\hline Konsumen suka & Kuning & & 0,423 \\
\hline Konsumen tidak suka & Kuning & & 0,423 \\
\hline$\Delta \mathrm{E}$ rendah & Merah & $\theta$ & 0,262 \\
\hline oHue merah & Merah kekuningan & $\overline{2}$ & $-0,0103$ \\
\hline
\end{tabular}

Tabel 3. Parameter mutu yang mempengaruhi perubahan warna indikator

Tabel 3 menunjukkan bahwa parameter yang berpengaruh terhadap perubahan warna indikator kemasan cerdas yaitu hedonik, nilai $\Delta \mathrm{E}$, dan nilai ${ }^{\circ} \mathrm{Hue}$. Pada parameter mutu hedonik terdapat dua parameter yang berbeda namun menghasilkan perubahan warna yang sama. Menurut [4] menyatakan hasil uji organoleptik produk susu sejalan dengan perubahan warna indikator kemasan cerdas. Pada saat konsumen tidak suka maka di waktu yang sama warna indikator kemasan cerdas berubah menjadi kuning. Oleh karena itu hubungan antara "konsumen suka" dan " indikator berwarna kuning" merupakan hubungan yang tidak valid dengan kondisi real.

Dengan menggunakan metode ReliefF, peneliti dapat memilih atribut parameter yang penting dari sekian banyak parameter yang ada. Berdasarkan hasil dari metode ReliefF, parameter yang penting dan cukup menggambarkan hubungan dari perubahan warna dan perubahan mutu produk disajikan pada Tabel 4.

\begin{tabular}{|c|c|c|}
\hline Parameter Mutu & Warna Indikator & Visualiasi \\
\hline Konsumen tidak suka & Kuning & \\
\hline$\Delta \mathrm{E}$ bernilai rendah & Merah & \\
\hline oHue berwarna merah & Merah kekuningan & $x$ \\
\hline
\end{tabular}

Tabel 4. Hubungan sebab akibat perubahan warna dengan perubahan mutu produk 


\section{Kesimpulan}

Dalam penelitian ini dapat disimpulkan bahwa parameter yang berpengaruh terhadap penelitian ini meliputi parameter perubahan warna indikator kemasan cerdas yaitu ${ }^{\circ} \mathrm{Hue}$, nilai $\Delta \mathrm{E}$, perubahan warna indikator, dan parameter perubahan mutu produk meliputi nilai uji organoleptik dan total koloni produk.

Pemilihan atribut dengan menggunakan metode Relief menunjukkan bahwa terdapat tiga atribut dengan nilai bobot $\left(\mathrm{W}_{\mathrm{i}}\right)$ tertinggi. Parameter mutu nilai organoleptik (kesukaan konsumen), $\Delta \mathrm{E}$, dan nilai ${ }^{\circ}$ Hue merupakan parameter yang penting dan cukup menggambarkan hubungan dari perubahan warna dan perubahan mutu produk.

\section{Daftar Pustaka}

[1] P. Taoukis, K. Koutsoumanis, G. Nychas, "Use of time temperature integrators and predictive modelling for shelf life control of chilled fish under dynamic storage conditions," IJ Food Microb, vol. 53, pp. 21-31, 1999.

[2] F.T. Mendoza, "Kinetic parameter estimation of time temperature integrators intended for use with packaged fres seafood," M.S. thesis, University of Florida, Florida, United State, 2003.

[3] Y. Hasnedi, B. Riyanto, A. Maddu, "Kemasan cerdas pendeteksi kebusukan filet ikan nila," PHPI, vol 8, pp.129-142, 2010.

[4] R. Nofrida, "Film indikator warna daun erpa (Aerva sanguinolenta)sebagai kemasan cerdas untuk produk rentan suhu dan cahaya," M.S. thesis, Institut Pertanian Bogor, Bogor, Indonesia, 2013.

[5] E. Bobelyn, M. Hertog, Nicolaï, "Applicability of an enzymatic time temperature integrator as a quality indicator for mushrooms in the distribution chain," JPBT, vol 42, pp. 104-114, 2006.

[6] E Warsiki dan C.D.W. Putri, "Pembuatan label/ film indikator warna dengan pewarna alami dan sintetis," E-J Agroin Indonesia, vol 1, pp. 82-87, 2012.

[7] H. Vaikousi, C. Biliaderis, K. Koutsoumanis, "Applicability of a microbial time temperature indicator (tti) for a monitoring spoilage of modified atmosphere packed minced meat," IJ Food Microb, vol 133, pp. 272-278, 2009.

[8] M. Ellouze and J. Augustin, "Applicability of biological time temperature Integrators as Quality and Safety Indicators for Meat Products," IJ Food Microb, vol 138, pp. 119-129, 2010.

[9] E. Warsiki and A. Setiautami, "Color stability of beat dyes label during heating," in Proceedings of International Conference on Adaptive and Intelligent Agroindustry, 2013, pp. 213-219.

[10] Liu and Huan, "Feature Selection : An Ever Evolving Frontier in Data Mining," in JMLR : Workshop and Conference Proceedings, 2010, pp. 4-13.

[11] K. Kira and L. Rendell, "The feature selection problem: traditional methods and a new algorithm," in AAAI-92 Proceedings, 1992.

[12] D.A. Irawan, Z.A. Baizal, E.G. Perdana, "Analisis dan Implementasi Algoritma Relieff untuk Feature Selection pada Klasifikasi Dataset Multiclass," M.S. thesis, Universitas Telkom, Jakarta, Indonesia, 2011. 